Ann. Zootech., 1973, $22(2), 237-242$.

NOTE

\title{
UTILISATION DIGESTIVE \\ D'ALIMENTS D'ALLAITEMENT CONTENANT DES LACTOSÉRUMS DE DIFFÉRENTES QUALITÉS PAR LE VEAU PRÉRUMINANT A L'ENGRAIS
}

\author{
J.-L. PARUELle, R. TOULlEC et C.-M. MATHIEU \\ Station de Recherches zootechniques, \\ Centre de Recherches de Rennes, I. N.R. A., \\ 65, rue de Saint-Brieuc, \\ 35042 Rennes
}

avec la collaboration technique de Marguerite Beaufils, J. Larfynie et Yvette Lento

RÉSUMÉ

Deux aliments d'allaitement, contenant 20 p. Ioo de lactosérum doux ou de lactosérum acide neutralisé par addition de chaux, ont été distribués chacun à 3 veaux préruminants à l'engrais élevés en cages à bilan entre les âges de 8 et roo jours. L'appétit, la croissance, l'efficacité alimentaire et les résultats d'abattage ont été satisfaisants pour les deux régimes. La fréquence des diarrhées a été faible dans les deux cas, en particulier avec l'aliment contenant le lactosérum acide et neutralisé. La richesse en calcium de cet aliment a cependant entraîné une baisse de la digestibilité des matières grasses de l'aliment qui est probablement due à la formation, dans la lumière intestinale, de complexes insolubles entre le calcium d'une part, le phosphore et les acides gras longs saturés alimentaires d'autre part.

Le lactosérum séché constitue pour le veau préruminant une source alimentaire riche en lactose et en minéraux, mais relativement pauvre en matières azotées (respectivement de l'ordre de 75,9 et $\mathrm{I}_{3} \mathrm{p}$. Ioo de la matière sèche). Ses protéines présentent un bon équilibre en acides aminés indispensables (Pion et FAUCONNEAU, 1966) et leur digestibilité apparente chez le veau est élevée : 9o à 93 p. roo (Toullec et al., 1969; Toullec et Mathieu, 197I). Actuellement, la poudre de lactosérum est couramment incorporée à raison de 5 à 1o $\mathrm{p}$. Ioo dans les aliments d'allaitement qui contiennent en outre 50 à $70 \mathrm{p}$. Ioo de lait écrémé et il peut être économiquement intéressant de l'incorporer à des taux plus élevés. Par ailleurs, elle représente la principale source de lactose disponible pour la réalisation d'aliments d'allaitement contenant des protéines de remplacement d'origine non laitière. Cette possibilité suppose une meilleure connaissance du pouvoir diarrhéique du lactosérum. En effet, pour certairs auteurs, il a chez le veau préruminant 
une influence laxative due à sa forte concentration minérale (OWEN et al., I958; BusH et al., I963), mais ces inconvénients n'ont pas été signalés par LadRaT et Jousselin (I968) et par Solms (I968) avec des aliments d'allaitement contenant I 5 à 20 p. Ioo de poudre de lactosérum. Il est de plus nécessaire de préciser les conséquences nutritionnelles de l'utilisation de lactosérums de différentes qualités. Du fait de leur origine, certains lactosérums subissent une acidification lactique importante qui rend nécessaire une neutralisation avant leur séchage. Dans les études réalisées sur l'utilisation par le veau de lactosérums acides neutralisés ou non (FISHER, I966; LADRAT et Jousselin, I968; Solms, I968), la teneur en acide lactique n'est jamais précisée et l'influence sur l'utilisation digestive n'est pas envisagée.

Nous avons donc mesuré, chez le veau préruminant à l'engrais, l'utilisation digestive de deux laits de remplacement obtenus à partir d'aliments d'allaitement contenant 20 p. Ioo de lactosérum séché par le procédé Spray (tabl. I). Dans l'un des aliments (aliment Lactosérum doux), il s'agissait d'un lactosérum à $I 7^{\circ}$ Dornic, issu de la fabrication de fromages à pâte molle, écrémé, pasteurisé et non neutralisé. Dans l'autre aliment (aliment Lactosérum neutralisé), il s'agissait d'un lactosérum à $72^{\circ}$ Dornic, issu de la fabrication de fromages à pâte fraîche, écrémé, pasteurisé et neutralisé à $18^{\circ}$ Dornic par addition de chaux.

\section{TABLEAU I}

\section{Composition des aliments}

Constituants (p. Ioo des 2 aliments)

Lactosérum .......... 20,0

Lait écréré $\ldots \ldots \ldots \ldots . \quad 53,8$

Amidon prégélatinisé $\ldots . . .3,0$

Suif $\ldots \ldots \ldots \ldots \ldots \ldots \ldots$

Lactosérum enrichi en ferments lactiques $\ldots \ldots \ldots \ldots$ 2,0

Huile de coprah $\ldots \ldots . .4,5$ Complément minéral et vitaminique (identique pour les 2 aliments) $\ldots \ldots \ldots, 3,0$

\begin{tabular}{|c|c|c|c|c|}
\hline \multirow{2}{*}{$\begin{array}{l}\text { Composition chimique } \\
\text { (p. } 100 \text { de la matiere sèche) }\end{array}$} & \multicolumn{2}{|c|}{ Lactosérums } & \multicolumn{2}{|c|}{ Aliments } \\
\hline & doux & neutralisé & $\begin{array}{l}\text { Lactosérum } \\
\text { doux }\end{array}$ & $\begin{array}{l}\text { Lactosérum } \\
\text { neutralisé }\end{array}$ \\
\hline Matières azotées .......... & 13,2 & 15,1 & 23,6 & $24,{ }^{\prime}$ \\
\hline Matières grasses $\ldots \ldots \ldots \ldots$ & 0,8 & 1,3 & 18,1 & 18,5 \\
\hline Substances réductrices . . . . . . & 70,1 & 63,1 & 42,4 & 38,1 \\
\hline Acide lactique $\ldots \ldots \ldots \ldots \ldots$ & 2,8 & 8,5 & 0,4 & 3,2 \\
\hline Matières minérales . . . . . . . & 9,1 & 11,8 & 6,5 & 7,9 \\
\hline Phosphore ............... & 0,8 & 0,9 & 0,7 & 0,8 \\
\hline Calcium $\ldots \ldots \ldots \ldots \ldots \ldots$ & 0,9 & $2, \underline{y}$ & 0,9 & 1,5 \\
\hline Sodium $\ldots \ldots \ldots \ldots \ldots \ldots$ & 0,7 & 0,7 & 0,4 & 0,4 \\
\hline Potassium . . . . . . . . & 2,1 & 1,9 & 1,1 & 1,1 \\
\hline 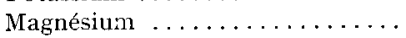 & 0,1 & 0,1 & 0,1 & 0,1 \\
\hline Fer (p.p.m.) $\ldots \ldots \ldots \ldots \ldots \ldots$ & 6,8 & 10,4 & 7,1 & 10,2 \\
\hline Cuivre (p.p.m.) $\ldots \ldots \ldots \ldots \ldots$ & 7,3 & 11,6 & 8,4 & 15,2 \\
\hline
\end{tabular}

Chacun des aliments a été distribué à 3 veaux de race Française Frisonne Pie-Noire achetés à l'âge d'environ 8 jours et placés en cages à bilan dès leur arrivée. Les mesures ont commencé I 3 jours plus tard et ont alors été effectuées pendant 6 périodes successives de I I jours séparées par des interpériodes de 3 jours. Les aliments d'allaitement ont été dilués dans de l'eau à $40^{\circ} \mathrm{C}$ et les laits de remplacerent ainsi préparés ont été distribués au seau 2 fois par jour. Les quantités offertes aux animaux étaient importantes et comparables à celles qui sont habituellement distribuées aux veaux à l'engrais. Le détail du rationrement airsi que des mesures, des dosages et des 
calculs effectués a été décrit précédemment (PARUELLE et al., 1972). Le dosage des matières grasses a été réalisé sur les aliments et les refus par extraction par le mélange chloroforme-méthanol selon le principe de la méthode de Folch, Lees et Sloane-STanley (I957) et sur les fèces par extraction par l'éther éthylique après hydrolyse chlorhydrique à chaud. La teneur en acide lactique a été déterminée d'après la méthode de BARker (1957). Le phosphore a été dosé par colorimétrie du phospho-vanado molybdate d'ammonium et les autres éléments par spectrophotométrie d'absorption atomique (appareil Unicam SP go A). Les animaux ont été abattus à la fin de l'expérience, 98 à roo jours après leur arrivée.

Les 2 aliments ont été bien consommés et ont permis des croissances élevées. L'état sanitaire a toujours été satisfaisant et la fréquence des diarrhées a été très faible avec les deux régimes, en particulier avec l'aliment Lactosérum neutralisé (tabl. 2). L'aliment Lactosérum doux a provoqué un état relâché plus fréquent. Ces résultats sont en accord avec ceux de Brows, READ et Williard (I953) qui ont montré l'effet préventif de la chaux dans le cas de diarrhées d'origine nutritionnelle du veau. Par ailleurs, lors de l'abattage, le randement en carcasse, l'état d'engraissement et la coloration de la viande ont été satisfaisants et identiques dans les deux cas.

\section{TABLEAU 2}

Croissance, consommation, utilisation digestive des laits de remplacement, rétention azotée et phosphocalcique

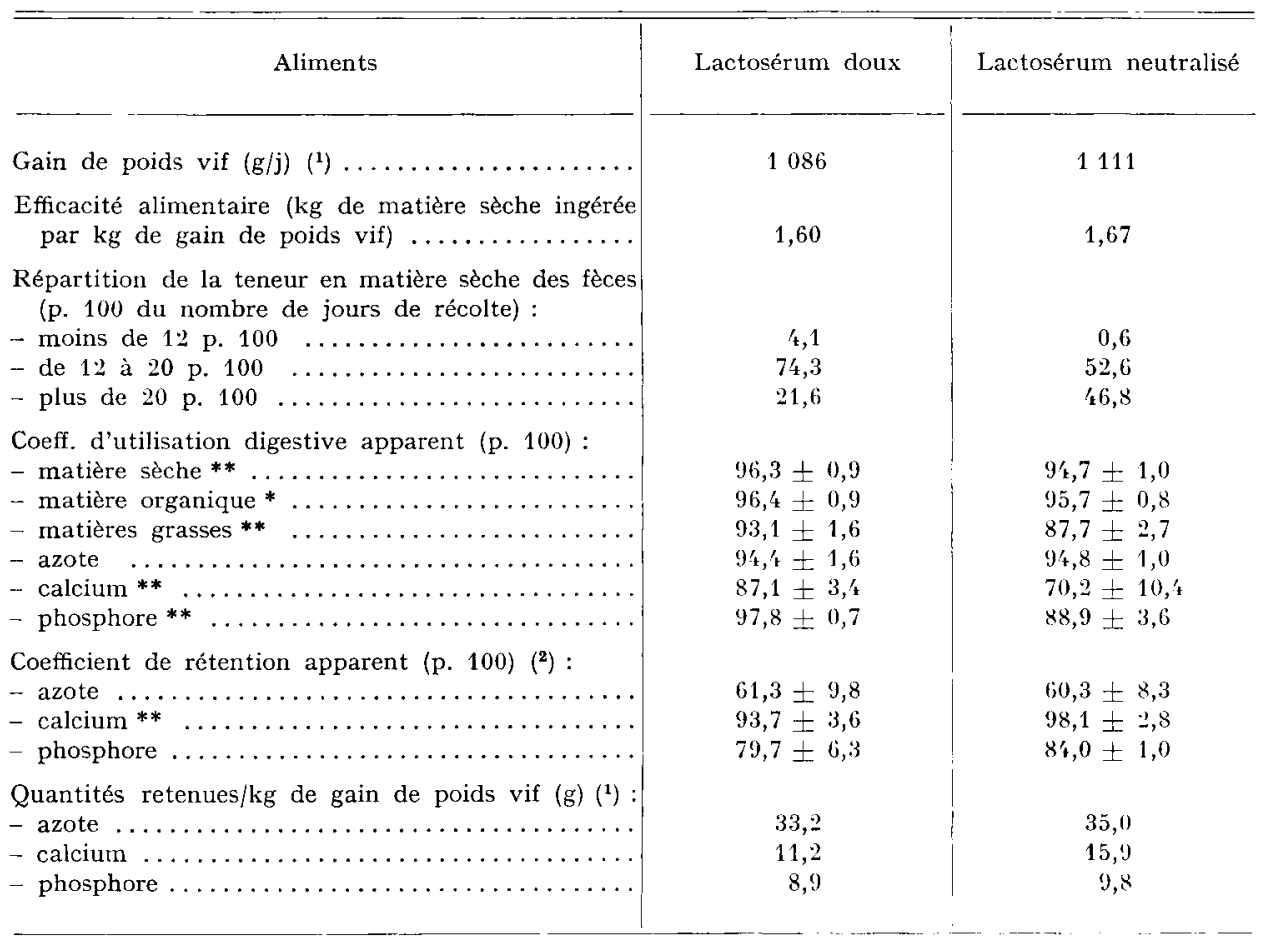

(1) Pendant les 81 jours d'expérience.

(2) Moyenne et écart-type des 6 périodes de mesure.

* Significativement différent au seuil $P \leqslant 0,05$.

** Significativement différent au seuil $P \leqslant 0,01$. 
Le coefficient d'utilisation digestive (CUD) apparent de la matière organique des deux aliments a été élevé (tabl. 2). Ses variations ont surtout été liées à celles de la digestibilité des matières grasses. En effet, le CUD des matières grasses s'est maintenu constant $(93, \mathbf{I}$ p. roo) pour l'aliment Lactosérum doux, alors qu'il a diminué de 91, I lors de la première période de mesure à $87,7 \mathrm{p}$. Ioo lors de la sixième période pour l'aliment Lactosérum neutralisé (fig. I). Dans le même temps, le CUD apparent du calcium a diminué de 88,9 à 83,5 p. Ioo pour l'aliment Lactosérum doux et de 83,2 à 56,9 P. Ioo pour l'aliment Lactosérum neutralisé. Le CUD apparent du phosphore est resté constant $(87,8 \mathrm{p}$. хоo) pour l'aliment Lactosérum doux et a diminué de 92,8 à $86,0 \mathrm{p}$. Ioo pour l'aliment Lactosérum neutralisé. Par suite de la teneur en calcium plus élevée de l'aliment Lactosérum neutralisé, on observe donc une digestibilité apparente moins élevée des matières
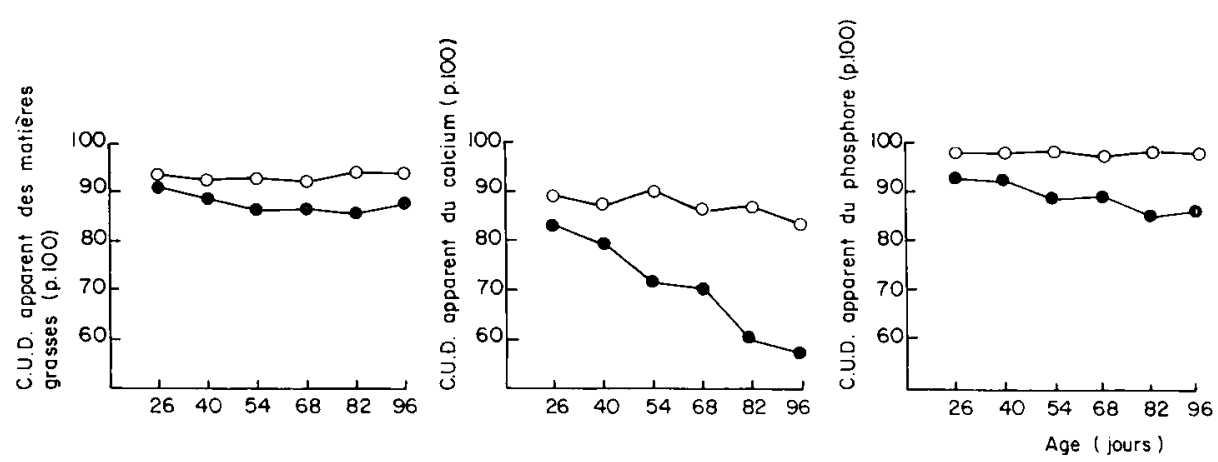

FIG. I. - Évolution des coefficients d'utilisation digestive apparents des matières grasses, du calcium et du phosphore avec l'áge

- - 0 Aliment Lactosérum doux

- Aliment Lactosérum neutralisé

grasses et du phosphore de cet aliment, ce qui serait dû principalement à la formation accrue, dans la lumière intestinale, de complexes insolubles entre le calcium d'une part, le phosphore et les acides gras longs saturés alimentaires d'autre part (CARRoll et RICHARDS, I958; Raven et Robinson, i96o et I964; Toullec, Flanzy et Rigaud, i968; Fakambi, Flanzy et François, I969). Cependant, la diminution de la digestibilité apparente du calcium qui est également observée, aurait probablement eu lieu en l'absence d'augmentation des quantités de complexes insolubles formés (Yacowitz et al., 1967). En effet, l'accroissement des quantités d'acides gras fécaux, s'il était réalisé uniquement sous forme de savons de calcium, n'expliquerait au maximum que $75 \mathrm{p}$. Ioo du calcium fécal supplémentaire en moyenne pour l'ensemble de l'essai. GútGuen (I964) et GúfGuen et Mathieu ( 1962 et 1965) ont d'ailleurs montré que, chez le veau, la régulation de l'utilisation du calcium se fait presque exclusivement au niveau de l'absorption intestinale, alors que celle du phosphore se fait principalement par l'élimination urinaire. En outre, les deux aliments différaient également par leur teneur en lactates dont on ignore l'influence sur la digestibilité des matières grasses du calcium et du phosphore.

Les quantités de calcium retenues par $\mathrm{kg}$ de gain de poids vif, et dans une moindre mesure celles de phosphore, ont été plus importantes chez les animaux recevant l'aliment Lactosérum neutralisé. Cet aliment a donc permis de réaliser une meilleure minéralisation osseuse que l'aliment Lactosérum doux. Cependant, sa teneur en calcium a paru excessive. Bien qu'insuffisante, la teneur en calcium de l'aliment Lactosérum doux peut donc être considérée comme satisfaisante puisqu'elle a permis une vitesse de croissance sensiblement égale à celle des animaux recevant l'aliment Lactosérum neutralisé sans occasionner le même effet dépressif sur la digestibilité des matières grasses.

Il paraît donc possible d'incorporer dans les aliments d'allaitement des taux importants de 
lactosérum doux ou neutralisé par addition de chaux sans observer d'effets défavorables sur la croissance des animaux ni sur la fréquence de l'état diarrhéique. La teneur élevée en calcium du lactosérum neutralisé entraîne cependant une baisse de la digestibilité des matières grasses de l'aliment. Cet inconvénient n'existerait pas avec des aliments d'allaitement contenant certaines protéines de remplacement pauvres en calcium (levures d'alcanes par exemple).

Ręu pour publication en décembre 1972.

\section{REMERCIEMENTS}

Nous adressons nos vifs remerciements à l'Union des Coopératives Agricoles d'Alimentation du Bétail (Chierry - o240o Château-Thierry) pour l'aide qu'elle nous a apportée à l'exécution des analyses.

\section{SUMMARY}

\section{DIGESTIVE UTILIZATION OF MILK SUBSTITUTES CONTAINING WHEY OF DIFFERENT QUALITIES BY PRERUMINANT FATTENING CALVES}

Two milk substitutes containing 20 p. I oo sweet whey or acid whey neutralized by addition of lime were given to 3 preruminating fattening calves kept in balance crates between the ages of 8 and roo days. Appetite, growth, feed efficiency and slaughter quality were satisfactory for the two diets. The frequency of diarrhoea was low in the two cases, in particular with the feed containing the acid and neutralized whey. However, the high calcium content of this feed brought about a lowering in the digestibility of dietary fats. This was probably due to the formation, in the intestinal lumen, of insoluble complexes between calcium on the one hand and phosphorous as well as/saturated long chain fatty acids on the other hand.

\section{RÉFÉRENCES BIBLIOGRAPHIQUES}

BARker S. B., 1957. Preparation and colorimetric determination of lactic acid. In Colowick S. P., Kaplan N. O., Methods in enzymology, vol. 3, 24I-246. Academic Press, New York.

Brown D. C., READ J., Williard H. S., I953. Slacked lime as a preventive of scours for whey-fed calves. J. Dairy Sci., 36, 3I9-324.

Bush L. J., Schuh J. D., Tennille N. B., Waller G. R., i963. Effect of dietary fat and minerals on the incidence of diarrhea and rate of passage of diets in the digestive tract of dairy calves. J. Dairy Sci., 46, 703-709.

Carroll K. K., Richards J. F., r958. lactors affecting digestibility of fatty acids in the rat. J. Nutr., 64, 4II-424.

Fakambi L., Flanzy J., François A. C., I 969 . Compétition in vivo entre acides gras et phosphore pour la formation de composés insolubles de calcium. C. R. Acad. Sci., Paris, 269, série D, 2233-22j5.

FISCHER Von W., Ig66. Molkenpulver aus der Speisequarkherstellung in der Kälbermast. Milchwissenschaft, 21, 770-772.

Folch J., Lees M., SloAne-Stanley G. H., I957. A simple method for the isolation and purification of total lipids from animal tissues. J. Biol. Chem., 226, 497-509.

Guḱguen L., I964. Le métabolisme du calcium et du phosphore chez le veau recevant du lait entier enrichi en éléments minéraux. C. R. Acad. Sci., Paris, 258, série D, 5985-5988.

Guéguen L., Mathieu C.-M., I962. L'utilisation des éléments minéraux de la ration par le veau. I. Influence du régime alimentaire. Ann. Zootech., 11, II5-I34.

Guḱguen L., Matueu C.-M., I 965. . L'utilisation dos éléments minéraux de la ration par le veau. II. Influence du niveau de l'apport phospho-calciqus, Ann. Zootech., 14, 23 I-245. 
Ladrat J., Jousselin W., r968. Emploi de la poudre de lactosérum dans les aliments d'allaitement pour veaux de boucherie. Bull. Acad. Vét. Fr., 41, 57-65.

Owen F. G., Jacobson N. L., Allen R. S., Homeyer P. G,, 1958. Nutritional factors in calf diarrhea. J. Dairy Sci., 41, 662-670.

Paruelle J.-L., Toullec R., Frantzen J.-F., Mathieu C.-M., I972. Utilisation des protéines par le veau préruminant à l'engrais. I. Utilisation digestive des protéines de soja et des levures d'alcanes incorporées dans les aliments d'allaitement. Ann. Zootech., 21, 3I9-33I.

Pion R., Fauconneau G., I966. Les acides aminés des protéines alimentaires. Méthodes de dosage et résultats obtenus. Amino-acides, Peptides, Protéines, A. E. C., Société de Chimie Organique et Biologique. Cahier no 6, I58-175.

Raven A. M., Robinson K. L., I960. Studies of the nutrition of the young calf. III. A comparison of unhydrogenated palm-kernel oil, hydrogenated palm-kernel oil, and butterfat, as constituents of a milk diet. Brit. J. Nutr., 14, I35-146.

Raven A. M., Robinson K. L., I964. Factors affecting the nutritive value of fat for calves. II. The system of feeding, and the mode of incorporation into meal mixtures. J. Sci. Fd Agric., 15, 2 I9-227.

SolmS G., I968. Kälbermastversuche zur Eignungsprüfung verschiedener Sauermolkenpulver als Milchaustauschfuttermittelkomponente. Molkerei -und Käserei-Zcitung, Hildesheim, 19, 452-456.

Toullec R., Mathiev C.-M., I97i. Utilisation des protéines du lactosérum par le veau préruminant à l'engrais. Symposium international sur l'engraissement du veau. Prague.

Toullec R., Mathieu C.-M., Vassal L., Pion R., I969. Utilisation digestive des protéines du lactosérum par le veau préruminant à l'engrais. Ann. Biol. anim. Bioch. Biophys., 9, 661-664.

Toullec R., Flanzy J., Rigaud J., I968. Dosage des lipides des fèces ; extraction séparée, importance et composition en acides gras des lipides non saponifiés et de ceux des complexes insolubles. Ann. Biol. anim. Bioch. Biophys., 8, 28I-289.

Yacowitz H., Theischman A. I., Amsden R. T., Bierenbaum M. L., I967. Effect of dietary calcium upon lipid metabolism in rats fed satured or insatured fat. $j$. Nutr., 92, 389-392. 